\title{
Determination of selenium in rat brain by synchrotron radiation $\mathrm{X}$-ray fluorescence
}

\author{
N. Schulmann-Choron ${ }^{1 *}$, P. Chevallier ${ }^{2}$, J. de Ceaurriz ${ }^{3}$ and Ch. Souleau ${ }^{1}$ \\ ${ }^{1}$ Laboratoire de Chimie Physique Minérale et Bioinorganique, Faculté de Pharmacie de Châtenay-Malabry, \\ 5 rue Jean-Baptiste Clément, 92296 Châtenay-Malabry Cedex, France \\ ${ }^{2}$ LPS, Laboratoire Pierre Süe, CEA/CNRS, CEA Saclay, LURE (Laboratoire pour l'Utilisation \\ du Rayonnement Electromagnétique), Centre Universitaire Paris-Sud, 91898 Orsay Cedex, France \\ ${ }^{3}$ Laboratoire de Toxicologie de l'Environnement, Faculté de Pharmacie de Châtenay-Malabry, \\ 5 rue Jean-Baptiste Clément, 92296 Châtenay-Malabry Cedex, France
}

\begin{abstract}
Selenium, an ubiquitous essential trace-element, is known to be particularly difficult to measure especially in brain. First, it is a non metal, next, at very low concentration (below ppm); at last, the brain matter, very rich in lipids, make the digestion specially uneasy. Using synchrotron radiation induced X-ray fluorescence analysis (SXRF), selenium in rat brain was measured equal to $\mathrm{C}_{\mathrm{Se}}=124 \pm 5.4 \mathrm{ppb}$ with a MDL (minimum detection limit) of $20 \mathrm{ppb}$. The obtained values should be used as a first step to study human brain on extremely small and specific locations. With the development of aging pathologies (such as Alzheimer's or Parkinson's disease...), it matters to get informations about selenium known as an anti-aging element. The obtained values from rat, near of man's, may also highlight it as a potential animal model system for studying selenium in human brain.
\end{abstract}

Keywords: Selenium - brain - rat - X-ray fluorescence - synchrotron.

\section{Introduction}

\section{Selenium}

If selenium entered in history in 1295 through the memoirs of Marco Polo when his horses died after eating a dangerous plant, the astragalus, it took 500 years before the cause could be attributed to its selenium content.

First known for its toxicity, selenium was recognised only recently as a vital trace element [1]. Its essentiality was proved first for animals [2] in 1978, then for man, in 1979, with the eradication of the congestive cardiomyopathy devastating the selenoprive chinese country of Keshan [3]. The death of patients under parenteral nutrition without selenium confirmed it in 1980 [4]. Since that period, many fundamental and clinical researchs were made about its potentialities, especially for chronical or degenerative diseases. Known as an immunitary defense and anti-aging element, it proved its importance against cancer and many others pathologies where it occurs generally through a loss [2]. Its major role is to protect cells membranes. At present time, lots of treatments include it as a supplementation in food [5].

In human body, selenium is found in different molecules, but principally as glutathione peroxydase (GSHPx) cofactor. This enzyme takes place in the regulation cycle of oxygen free radicals (Fig. 1), Selenium plays a lead in man and mammalian organism. The GSHPx contributes to cell protection and its membranes through the breakdown of hydrogen peroxide $\mathrm{H}_{2} \mathrm{O}_{2}$ and fatty peroxides according to:

$$
\mathrm{ROOH}+2 \mathrm{GSH} \rightarrow \mathrm{ROH}+\mathrm{H}_{2} \mathrm{O}+\mathrm{GSSG}
$$

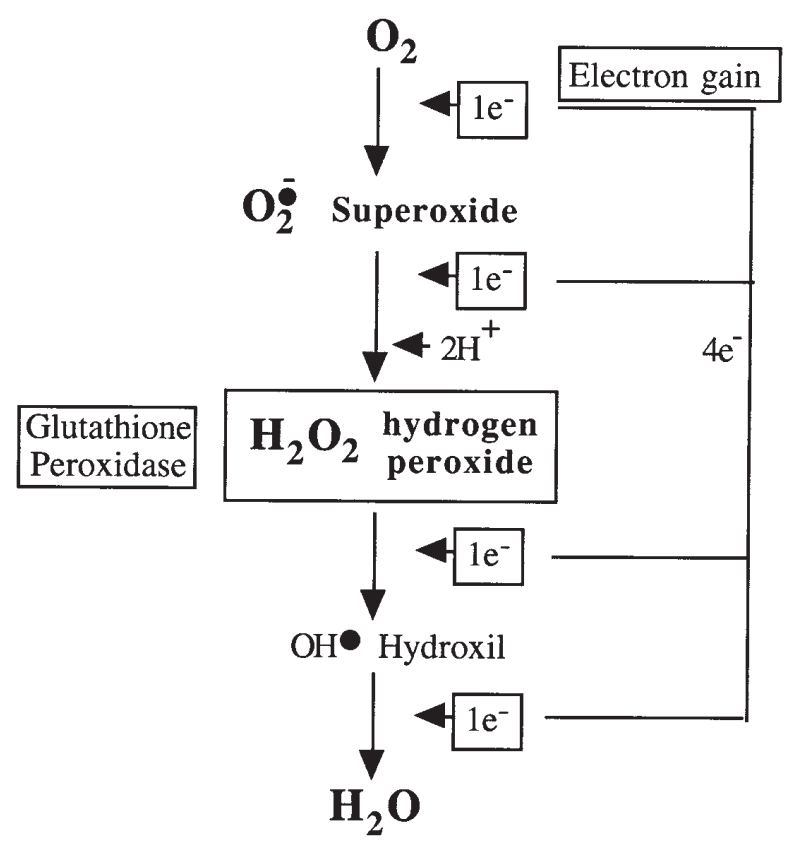

Figure 1. Regulation cycle of oxygen. 


\section{Trace element analysis}

As mentioned in a recent special issue about metals in biomolecules [6], until the late 80 ties, the study of inorganic trace elements was limited to the quantification of the element without taking into account the chemical modifications that may occur during the necessary high temperature destruction of the sample. It is now well known that the change of oxidation state plays determinant part during the enzymatic reactions and may produce abnormal effects if the element is present in an other oxided state than the expected one.

Later, new analytical techniques allowed to take more care of the element speciation. Selenium species was a problem encountered during the digestion of brain samples of this experience as seen later, but nevertheless needing a sample destruction.

A third step seems necessary to be considered: making measurements with non destructive methods for the sample. Then, this leads, in brain and perhaps in other tissues, to a forth one, the study of extremely small and precise areas, near cell's dimensions, in order to look at possible local concentration and species changes. It was effectively observed that selenium seems to show, in specific and very handicapating diseases, variations of concentration depending of the organ. Selenium homeostasy may favour some important organ, as brain, beside of others as blood... [7-9]. Nevertheless, glutathione peroxidase activity seems to stay unaffected in pathological brain and at the same time glutathione peroxidase activity seems to decrease in blood.

In living organ, selenium is typically well below the ppm level, say around 0,1 ppm. Our final aim is to measure this element content at the human cell level that is to say in no more than $\mu \mathrm{g}$ weight samples. The result, is a very low mass of selenium around pg. Only very special analytical techniques can reach such ultratrace level. This is one of the reasons that decided us to use X-ray fluorescence analysis excited by synchrotron radiation to perform our measurements.

Due to its emission from a particules accelerator the LURE (Laboratory for the Use of Electromagnetic Radiation) provides an exceptional photonic flux for the analysis by X-ray fluorescence. This allows a great sensitivity when the measured quantities are so small.

This experience was done as a first step to prepare measurements of selenium concentration and species on solid man brain samples by SXRF with non destructive methods on a third generation synchrotron facility. Paralelly, this work will be completed by a research of selenium species with X-Ray Absorption Spectrometry techniques such as XANES (X-Ray Absorption spectroscopy) and EXAFS (Extended X-Ray Absorption Near Edge Fine Structure).

\section{Materials and methods}

The first task was to develop a procedure for preparation of rat brain samples in order to quantify selenium through $\mathrm{X}$ ray fluorescence analysis excited by Synchrotron radiation.

\section{Preliminaries}

The values of trace element measures may easily be invalidated by the preparation of the samples and the experimental conditions. The preparation of samples was done after a careful review, for each step, of all the eventual causes of contamination and the way to remedy to each of them when possible. Most of the local contamination sources (air, water, protection dressing, jewels, cosmetics, smokes, gloves, tubes, tubes cap, purity of the reagents...) were tried to be avoid according to the best with the recommended counsels of the SFERETE (Société Francophone d'études et de Recherche sur les éléments Trace Essentiels) for traceelements measures [10] and the context opportunities.

Before measurements all tools were selected to avoid pollution of the sample during preparation. We proceeded to a preliminary test in order to verify if stainless steel did not introduce any contamination in brain by slicing some samples in several parts for our test. Some others, taken on the same rats, were considered as reference. We made 54 measurements in that aim.

As polypropylene is a matter also encountered, during the experiment, in tubes and eventually in film, an other test was done in order to avoid the possibility of pollution by tubes and to verify the possibility of realizing measures with polypropylene as substrat for brain samples.

A qualitative test on Cryomatrix, a kind of glue used to fix solid samples on their support, was also proceeded.

Another qualitative test was made to verify if glass, which is usualy used as a substrat for solid samples in microscopic analysis, does not bring trace elements contamination.

In the same way we have observed presence of selenium on histological rat brain microtome slices. No radiation defects could be seen after 10 minutes measurement.

\section{Rat brain sampling and sample preparation}

Brains were taken on males Sprague Dawley rats from Charles River of 180 to $200 \mathrm{~g}$ weight boarded two months long in Châtenay-Malabry animal house so that their alimentation and live conditions don't introduce any error sources.

They lived in standard cages developed by the veterinary services receiving standard food AO4 from UAR (Usine Alimentation Rationelle). Locals were warmed at $18-20{ }^{\circ} \mathrm{C}$ and alighted from 7 to 19 hours by an automatic system. The room was discontaminated and disinfected twice a week with a non toxic product. Rats litter was changed and the animals also washed twice a week. Moreover, a total decontamination is done every year. 


\section{Original articles}

Brains were extracted immediately after death by decapitation. Scalps and skulls were cut with stainless steel scissors and then the brains were fractionned in 3 samples of 200 to $600 \mathrm{mg}$ with the help of disposable stainless steel PARAGON blades. Every samples were then set for a 24 hours lyophilisation in order to eliminate water from the tissues and stop selenium migration. The sample can then be stored for a longer time without alteration if necessary. Further, this lyophilisation creates channels in the sample leading to a larger contact area with the reagents, and thus, optimising the digestion step. Lyophilisation offers an other advantage as brain is containing about $60 \%$ of water and selenium mass in brain very low, the taking off water concentrate selenium in same proportion.

The digestion procedure should take account of the exceptional volatility of some Se compounds and the fact that we wish to transpose it later for routine measurements by AAS. Though different trials were made with oxidative digestion procedures inspired of the very complete review of Arnaud et al. [16].

Oxidation by the perchloric acid $\mathrm{HClO}_{4}$ was first eliminated because of explosions risks for the detector. The sulfuric acid $\mathrm{H}_{2} \mathrm{SO}_{4}$ was also left, oxidation created black carbon, which deposit on the lamp ray was an obstacle to the measurements. Coupled action of nitric acid and hydrogen peroxide gave the best result and may be used as it stands for SXRF.

The brain parts were directly weighed in polypropylene tubes. $200 \mathrm{ml}$ of nitric acid $\left(\mathrm{HNO}_{3} 65 \%\right.$ Ultrapur Normatom, analysis grade) and $50 \mathrm{ml}$ hydrogen peroxide $\left(\mathrm{H}_{2} \mathrm{O}_{2} 30\right.$ vol obtained by dilution from a 110 vol solution, analysis grade, RP Normapur, both from Prolabo) were added. These proportions are those found from classical acid digestion methods in the literature [11-15]. Finally, the tubes were placed in a drying cupboard at $60{ }^{\circ} \mathrm{C}$ during $12 \mathrm{~h}$. They were set in a specially constructed holder that would insure that the cap of the tubes would resist pressure overload without any gas leakage during the digestion process.

This procedure was adopted after test on different tissues, such as blood and brain, because selenium is known to give a volatile species especially in its +IV oxidation state. If a single nitric digestion is performed selenium compounds can be oxidised in the very volatile and toxic $\mathrm{SeO}_{2}$ form. Therefore, the acid digestion is done in presence of hydrogen peroxide that will bring selenium to the $+\mathrm{VI}$ oxidation state as non volatile $\mathrm{H}_{2} \mathrm{SeO}_{4}$ and final precaution, in a closed tube. Figure 2 shows the X-ray spectra obtained on two identical samples of blood. For the first one, before digestion was done and for the second one, after digestion was performed in an open tube. We can notice that selenium has completely disappeared from the second sample.

For quantitative analysis, the internal standard method was used by adding vanadium at a concentration level of $15 \mathrm{ppm}$ as a reference element in the final solution. It was chosen because no vanadium appears in our brain sample spectra. A $5 \mathrm{mM}$ sodium vanadate stock solution prepared

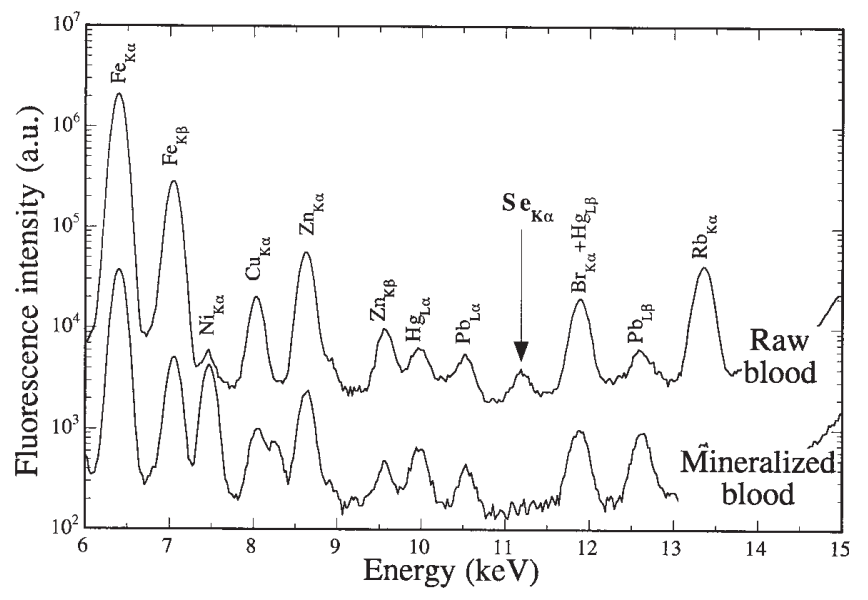

Figure 2. Spectra before and after digestion in open tube: The qualitative comparison of the two spectra immediately shows a lack of selenium in open tube digestion case. (Test on blood). Spectra acquisition time: $1000 \mathrm{~s}$.

from vanadium oxid $\mathrm{V}_{2} \mathrm{O}_{5}$ was used as a source of vanadium. The vanadate solution was prepared using the protocole of Gallagher and Leonard [16]. Then, the final solution was obtained by dilution. When using X-ray fluorescence, the vanadium speciation does not matter.

Finally, $4 \mu \mathrm{l}$ calibrated drops of this digested brain solution including the reference element where set to dry by evaporation at room temperature on a $1,5 \mu \mathrm{m}$ thick mylar film stretched on a slide frame. We had first test separately that the mylar film did not contained selenium before we decided to choose this material. At the last step of samples preparation for the LURE we used antistatic gloves in order to eliminate dust effect from the mylar and plastic slide frames.

This leads to an homogenous solid residue of about two $\mathrm{mm}$ diameter perfectly adapted to be analysed by the X-Ray beam.

\section{Experimental set up and analysis}

Selenium measurements were performed on the X-Ray fluorescence facility installed on beam line D15 of the LUREDCI synchrotron ring in Orsay (France). The white beam first reaches the monochromator. It consists of two crystals of highly oriented pyrolytic graphite $\left(\mathrm{FWHM}=0,4^{\circ}\right)$ operated in the parallel mode. The first one is a plane crystal that selects the energy with a wide band pass while the second one, due to its curved geometry, focuses the monochromatic beam on a spot of typically one millimeter diameter. The whole mechanic is under primary vacuum and all rotations and translations of the two crystals are remote controled from a PC computer. The focal spot is in the air and at a fixed position whatever the chosen energy is between 9 and $23 \mathrm{kev}$. 
Up to four slide frames, each with three different drops of typically five samples (total sixty drops) are fixed to a three axis (X, Y, Z ) Micro-control remote controlled stage: each drop is brought to the focal spot which is simulated by a laser beam and visualised on a colour TV screen through a microscope associated to a video camera. This allows to record the co-ordinates of each drop.

The X-ray fluorescence spectrum is recorded with a $\mathrm{Si}(\mathrm{Li})$ detector of $150 \mathrm{eV}$ energy resolution and $13 \mathrm{~mm}^{2}$ area. An aluminium collimator is installed on the detector axis for shielding and to limit the acceptance angle. Scattering in the detector is further reduced by placing it in the plane of the synchrotron ring and perpendicular to the incoming beam. Pulses from the preamplifier are sent to a Tenelec 244 amplifier and then processed through a Nucleus Multichannel Analyser card set in a PC computer.

Analysis of the whole set of drops can be performed automatically. The co-ordinates (X, Y and $\mathrm{Z}$ ) of each drops are stored in a file of the program PASECH. Then this one will automatically bring the sample in the right position, start and stop the acquisition after a preset time, give the spectrum a filename and store it. These operations are repeated until all drops have been analysed.

Finally, the program WAPI [17], a software which exploites X-Ray fluorescence spectra, is used for deconvolution of each spectrum. It gives a list of all elements observed and the net area of the representative peaks after correction of air absorption and detectors efficiency. These final values can be used for quantitative analysis.

\section{Results and discussion}

\section{Justification of the choice of an experimental facility}

Two very different kinds of analytical procedures can be thought for selenium measurement at trace element concentration level (see Tab. I and II). The first ones uses large facilities such as accelerator: PIXE (Particules Induced X-Ray Emission); nuclear reactors: NA (Neutron Activation) or electron ring storage: Synchrotron XRF (X-Ray Fluorescence). Others refer to much smaller apparatus like fluorimetry, AAS (Atomic absorption Spectrometry) or chromatography, HPLC (High performance liquid chromatography) or GC/MS (Gas Chromatography, Mass-Spectrometry) and can be found in many well equipped private laboratories or hospitals. The later ones are usually less costly, easier to handle and above all more available. A good review concerning selenium detection methods can be found in the literature [29].

PIXE needs important volumes of sample comparatively to SXRF and a preconcentration phase. The preparation technique of the sample before measurement is very delicate with its many steps. Moreover, the energy left by the particles in the target is relatively high and may destroy the sample or volatilize chemical species.

In Neutron Activation, a quite universal method, generally very sensitive, the implementation is very heavy. To obtain the same sensitivity than LURE's in the measurements, such important flux are needed that only some specific reactors can produce it. This method is not so easy to handle than SXRF, but it also may be used to calibrate or certify results obtained on smaller and more accessible apparatus of the second category. The measurement of one sample may take some days and careful precautions must be taken in radioactive substance manipulation. Moreover, samples having been treated by other nuclear facilities have became nuclear wastes and must not be reused.

On an other side, we may consider the lighter techniques. The EAAS (Electrothermic Atomic absorption Spectrometry) facilities with Zeeman effect and a L'vov platform are currently found and recommended for selenium detection. The measurement takes a short time and may be totally automated. Its practice requires an experimented technician; beside, the program adjustment may take a certain previous

Table I. Compared qualities of nuclear facilities for selenium detection in biology.

\begin{tabular}{|c|c|c|c|}
\hline Method & $N A$ & PIXE & $S X R F$ \\
\hline Principal Ref. & $\begin{array}{c}\text { Revel } 1999[26] \\
\text { Corrigan } 1991[20]\end{array}$ & Simonoff 1988 [28] & These tests 2000 \\
\hline All Tissues & $* * *$ & $* * *$ & $* * *$ \\
\hline MDL (ng) & $10^{-2}$ & 2 & $8.10^{-3}$ \\
\hline Multi-elementarity & $* * *$ & $* * *$ & $* * *$ \\
\hline Practibility & $*$ & $* *$ & $* * *$ \\
\hline Duration of very measurement & $* *$ & $* * *$ & $*$ \\
\hline Preparation steps for selenium & $\begin{array}{l}\text { - about } 3 \text { weeks } \\
\text { - Heavy preparation } \\
\text { - Important volume }\end{array}$ & $\begin{array}{l}\text { - Some days } \\
\text { - Heavy preparation } \\
\text { - Important volume }\end{array}$ & $\begin{array}{l}\text { - } 1 \text { day } \\
\text { - Simple preparation } \\
\text { - Very small volume }\end{array}$ \\
\hline
\end{tabular}

Practibility: *** easy *heavy

Duration: $* * *$ fast $*$ slow 


\section{Original articles}

Table II. Characteristics of some research laboratory methods for selenium detection in biology.

\begin{tabular}{|c|c|c|c|c|}
\hline Method & $E A A S$ & Fluorimetry & $G C / M S$ & HPLC \\
\hline Ref. & $\begin{array}{c}\text { Moynier } 1989 \text { [24] } \\
\text { Morisi } 1988 \text { [23] }\end{array}$ & $\begin{array}{c}\text { Alfthan } 1984 \\
{[19]}\end{array}$ & $\begin{array}{c}\text { Ducros } 1992 \\
{[21]}\end{array}$ & $\begin{array}{c}\text { Handelman } 1989 \\
{[22]}\end{array}$ \\
\hline Blood and derived & $* * *$ & $* * *$ & $*$ & $* *$ \\
\hline Tissues & $* * *$ & $\circ$ & $*$ & $*$ \\
\hline MDL (ng) & 0.041 & 0.45 & & 1.5 \\
\hline Practibility & $* *$ & $* *$ & $* *$ & $* *$ \\
\hline Cost & $*$ & $* * *$ & $* *$ & $* *$ \\
\hline Duration & $* * *$ & $* * *$ & $* *$ & $* *$ \\
\hline Notes & $\begin{array}{l}\text { - Middle time preparation } \\
\text { - Partial automatism } \\
\text { - Necessary experience }\end{array}$ & $\begin{array}{l}\text { - Long preparation } \\
\text { - Partial automatism }\end{array}$ & $\begin{array}{l}\text { - Middle time preparation } \\
\text { - Possible automatism } \\
\text { - Necessary experience }\end{array}$ & $\begin{array}{c}\text { - Middle time preparation } \\
\text { - Possible automatism } \\
\text { - Necessary experience }\end{array}$ \\
\hline
\end{tabular}

*** recommanded method for analysis laboratory

** working method

* method for specialised laboratory or with adjustments

- unexploited method

Duration : *** fast * slow

Cost : $\quad * * *$ low $*$ high

time. The chemical species used for the digestion before detection have an important influence on the program and on the possibilities of detection. The cost is high.

HPLC (High Performance Liquid Chromatography) is long and difficult to use and quite impossible to automate completely. Its cost is lower than EAAS's one.

Fluorimetry, easy to practice even without experience, is also much more cheaper but the detection results may be very long and difficult to obtain with tissues like brain. Lots of matrix rays may interfere with the element one.

The study of tables I and II shows that different methods may reach small concentrations but keeping in mind our aim to explore selenium at cell level, synchrotron XRF is the most appropriate. That is why we investigate in this technique.

\section{Preliminary tests}

It was observed that there was no evidence of contamination by materials used in samples preparation particularly with stainless steel, consequently stainless steel can be used for cutting brain.

Glass, even on very thin slide contained too many elements, making it totally inappropriate as backing for samples for the final purpose. On the contrary, mylar and polypropylene could be used, considering that they did not contain any contaminating element; we preferred mylar because of its mechanic properties.

Cryomatrix, showed no possible pollution by trace elements and could be selected for the next stage of the experimentation.

\section{Selenium measurements}

This experience represents a preliminary one for a study on human brain. Therefore, corollaries measurements between wet weight and dry weight were done directly on human brain. The results on different brain samples shows big variations from one to another (the ratio dry weight/wet weight was found in the range $13,6 \%$ to $29,2 \%$ ). Looking closely at the different values, it seems to appear that differences of moisture content have at least two factors: evaporation and part of the brain.

Here, for the rats, all the brain samples have been taken and treated at the same time, in the same conditions. Consequently, wet mass squares with fresh one, which is nearer to biological reality than dry one. Thus, we considered that the results for wet weight might be taken as a function for specimens.

Even though our detection method is very sensitive, the selenium peak observed on X-ray fluorescence spectra is usually small and seat on an important background (cf. Fig. 4). Then the error on this area is essentially due to uncertainty in deconvolution code used to extract the area. In our case, it is typically of about $15 \%$ and this is why 3 drops of each of the 3 different parts of 6 rat brains were prepared.

On each drop the ratio Se/V was measured and compared with the same ratio measured during the same set of experiment with standards of selenium diluted in $15 \mathrm{ppm}$ vanadium solution. This gives 51 values of selenium concentration in rat brain, the average of which is $124 \mathrm{ppb}$ with a standard deviation of $22 \mathrm{ppb}$.

Concerning the accuracy of the method, this result comes from statistical measurements. For a single measurement, it 


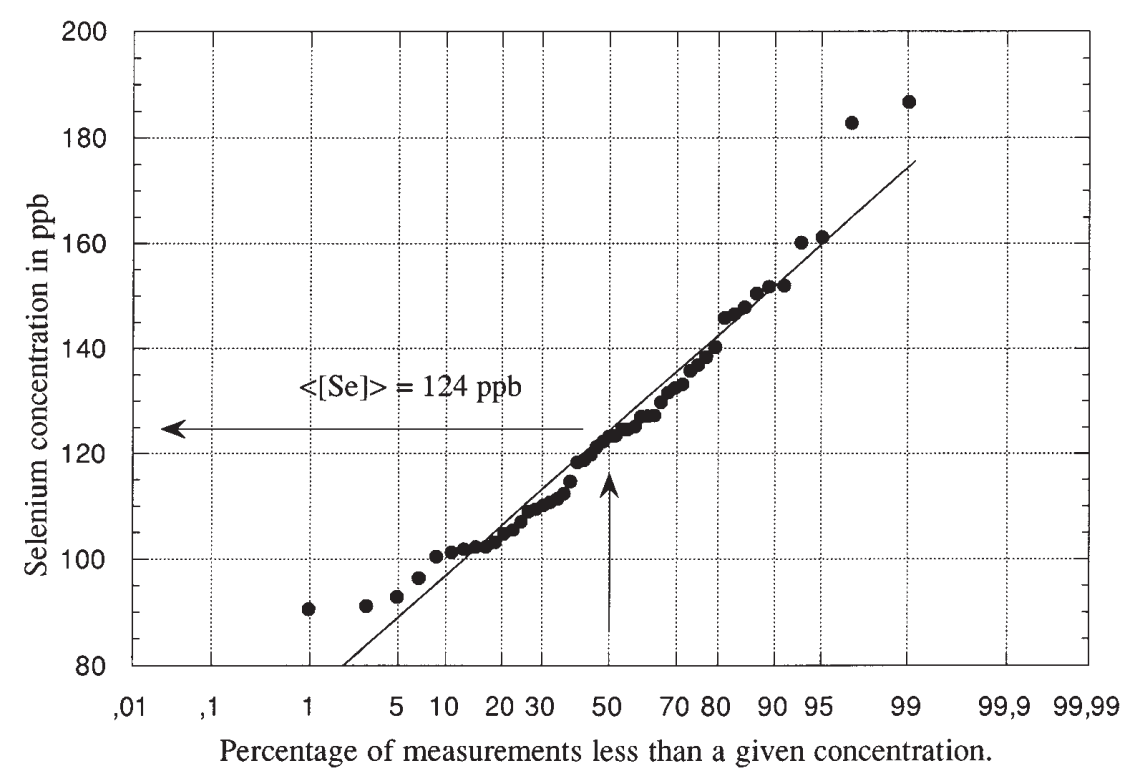

Figure 3. Test of consistancy of the experimental results: This test shows the distribution of the values in Henry plot pointing out the coherency of the measurements. would have been necessary to take into account the uncertainties coming from the spectrum decomposition.

Reproducibility and repeatability are usually excellent (typically less than $5 \%$ ) and have been previously measured [30].

To have an objective view of the consistency of the results, we choose to use the Henry's Law. This test eliminates the impact of the statistics in the obtained values. Displayed on that peculiar scale (PROBIT scale), data points fit well with a straight line. Though, the plot confirms the coherency of the distribution of the experimental results (Fig. 3) and it is justified to take the mean value of all measurements performed on individual rats.

If we consider mean value, the dispersion is very small because of the large part of the individual errors which was due to the deconvolution is somewhere averaged. This result may be consistent with the fact that all six rats were of the same family. A statistical treatment of the results on the six

Table III. Mean of selenium measurements in six individual rat brains and corolary statistics results.

\begin{tabular}{lcccc}
\hline Se) ppb & Sample 1 & Sample 2 & Sample 3 & $\langle$ Rat $\rangle$ \\
\hline Rat 1 & 127.3 & 121.0 & 94.7 & 114.3 \\
Rat 2 & 120.7 & 164.6 & 102.6 & 129.4 \\
Rat 3 & 115.1 & 138.5 & 120.9 & 124.8 \\
Rat 4 & 115.7 & 125.1 & & 120.4 \\
Rat 5 & 112.0 & 134.2 & 136.9 & 127.7 \\
Rat 6 & 117.9 & 129.3 & 139.5 & 128.6 \\
Mean & 118.1 & 135.4 & 118.9 & 124.1 \\
Median & 116.5 & 131.8 & 120.9 & 123.5 \\
Standard deviation & 5.36 & 15.58 & 20.02 & 5.38 \\
\hline
\end{tabular}

rats (cf. Tab. III) gives as a result for selenium concentration:

$$
\mathrm{C}_{\mathrm{Se}}=123.9 \pm 5.4 \mathrm{ppb} \text { (standard deviation) }
$$

which by noway means that a single individual measurement would fall between 118.5 and $129.3 \mathrm{ppb}$ nor that the same value would be found on different strains of rats.

Such a narrow distribution is particularly good for biological material even if we consider having observed some slight microheterogeneity in drops material, probably due to the lipidic difference between organic and aqueous phases.

Moreover, the distribution symmetry is very good since the mean value of $\mathrm{C}_{\mathrm{Se}}=123.9 \pm 5.4 \mathrm{ppb}$ is in perfect accordance with the median value, $\mathrm{Cm}_{\mathrm{Se}}=123.5 \mathrm{ppb}$.

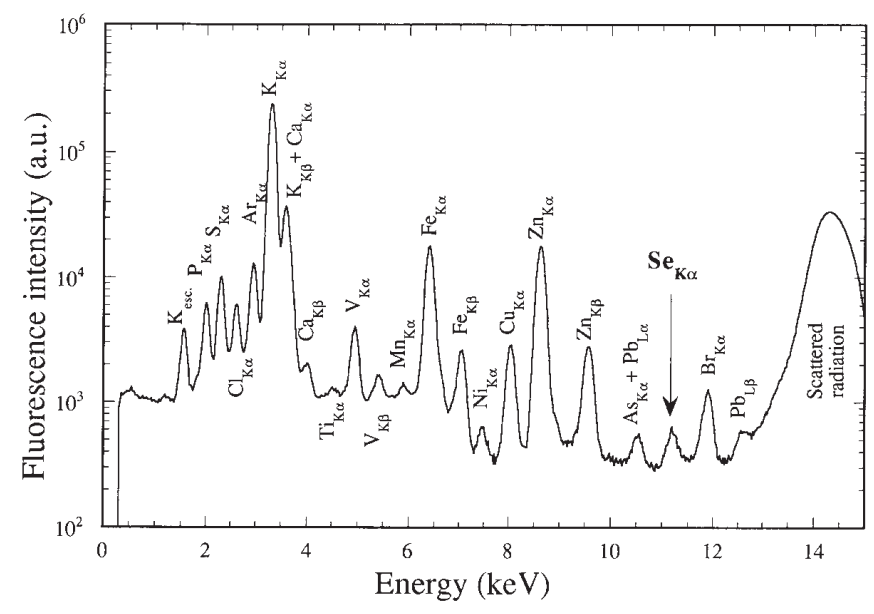

Figure 4. Rat brain spectrum used for MDL (Minimum Detection Limit) calculation. Spectrum acquisition time: $500 \mathrm{~s}$. 


\section{Original articles}

\section{Minimum detection limit (MDL)}

In X-ray fluorescence, the elemental concentration is proportional to the peak area $\mathrm{S}$. The element is considered to be detected when this peak can be distinguished against the background noise. The minimum detectable limit (MDL) correspond to the minimum measurable area $S_{\text {min }}$ which is taken as equal to three times the square root of this background. $\mathrm{MDL}=\mathrm{C}_{\mathrm{Se}}\left(\mathrm{S}_{\mathrm{min}} / \mathrm{S}\right)$.

Figure 4 presents a typical spectrum of rat brain. On this spectrum, we can estimate a MDL for selenium of:

$$
\mathrm{MDL}=20 \mathrm{ppb} .
$$

\section{Conclusion}

The mean selenium concentration value in 6 rat brains shows a relatively small dispersion for a biologic substance regarding to the statistical dispersion $\left(\mathrm{C}_{\mathrm{Se}}=123.9 \pm 5.4 \mathrm{ppb}\right)$ although relatively large fluctuations are observed on individual measurements due to the low concentration, the small sample mass and the error in spectrum deconvolution.

It offers a strong comparison with previous data: the experiments done by H.J. Robberecht et al. [6], in 1982 which gave $\mathrm{C}_{\mathrm{Se}}=140 \pm 40 \mathrm{ppb}$. In this case, selenium determination was investigated on rats labelled with ${ }^{75} \mathrm{Se}$ and through scintigraphy.

Our value is also near of that found in human brain on a representative German male subject, by Oster et al:: $\mathrm{C}_{\mathrm{Se}}=110 \pm 21 \mathrm{ppb}$ [30] measured with a model 5000, Perkin Elmer SAAH facility.

Therefore, concerning the element concentration, the rat may be regard as a pertinent animal model for studiyng selenium dependant brain pathologies.

The better choice of facility for this step is obviously SXRF with its simple preparation of samples, its flexibility and rapidity of response.

The MDL value equal to $20 \mathrm{ppb}$ is very low, confirming the interest of the chosen analytical method (SXRF).

This analysis has revealed two important points :

- First: major elements of biological samples (CHON) don't interfere with the measurements whereas this matrix effect greatly disturb with its background effect, the measurement through other methods such as AAS.

- Second: the detection method is non destructive. Further, using existing microbeam on third generation machines, we should be able to locate selenium in individual cells.

We think that a small number of measures, exceptionally done with the synchrotron, could validate experimental results obtained on more conventional materials which offer the possibility of routine measurements.

\section{Acknowledgments}

We are very grateful to Pr. J.J. Hauw for providing us with organic tissues and to Paul Teholaly for his counsels about tissues digestion and experienced information about EAAS.

We thank Nicolas Bonnet and Ventzislava Petrov for their involvement in data handling and poster presentation as well as Dr. Véronique Sazdovitch for valuable discussion about possible contamination of the sample and Pr. Perrière for the kindness of his help about the solid sample preparation.

We also wish to thank the LURE staff for their help and good running conditions.

\section{References}

1. Simonoff, M.; Simonoff, G. Le sélénium et la vie; Paris: Masson, 1991.

2. Chapuis, P. (co-ordinator), (SFERETE) Les Oligo-éléments en médecine et biologie; Paris: Lavoisier Tec \& doc., 1991.

3. Keshan Disease Group of The Chinese Academy of Medical Sciences Chinese Med. J. 1979, 92, 477.

4. Robinson, M.F.; Campbel, D.R. New Zealand Med. J. 1981, 683, 284.

5. Chapuis, P. (co-ordinator), (SFERETE) Les Oligo-éléments en nutrition et thérapie; Paris: Lavoisier Tec \& doc., 1995

6. Metals and Biomolecules, Foreword, Analusis 1998, 26 (6),

7. Kish, S. J.; Morito, C.L.H.; Hornykiewiecz, O. Neurochemical Pathology 1986, 4, 23-28

8. Lihua Chen.; Richardson, J. S; Caldwell, J. E; Lee, C. Ang. Intern J. Neuroscience 1994, 75, 83-90.

9. Perrin,R.; Briançon, S.; Jeandel, C.; Arthur, Y.; Minn, A.; Penin, F.; Siest. G., Gerontology 1990, 36, 306-313.

10. Baruthio, F.(co-ordinator). (SFERETE ), Assurance de qualité de l'analyse des Élements Trace en biologie; Paris: Lavoisier Tec \& doc., 1997.

11. Hoenig, M. Analusis 1991, 19, 41-46.

12. Koh, T-S.; Benson, T-H. J. Assoc. of Anal. Chem. 1983, 66(4), 918-925.

13. Robberecht, H.J.; Van Grieken, R.E.; Van Den Bosch, P.A.; Deelstra, H. and Van den Berghe, D. Talanta 1982, 29, 10251028.

14. Aadland, E.; Aaseth, J.; Radziuk, B.; Saced, K.; Thomassen, Y. Fresenius Z. Anal. Chem. 1987, 328, 362-366.

15. Dexter, D.T.; Wells, F.R.; Lees, A.J.; Agid, F.; Agid, Y.; Jenner, P. and Marsden, C.D. Journal of Neurochemistry 1989,18301836.

16. Arnaud J. et al. Ann. Biol. Clin. 1986, 44, 459-469.

17. Gallager, S. R.; Leonard, R.T. Plant Physiol. 1982, 70, 13351340.

18. Wang, J.X.; Piccot, D.; Chevallier, P.; Legrand, F. and Abbas $\mathrm{K}$. VIRESYME, logiciel de spectrometrie $\mathrm{g}$ et $\mathrm{X}$, Journées de Spectrométrie g et X, 12-14 Oct. 1993, St-Rémy-lesChevreuse, France, CEA note N-21756, 1994, 231-236.

19. Alfthan, G. Anal. Chem. Acta 1984, 165, 187-194

20. Corrigan F.M., Reynolds G.P.; Ward N.I. Trace Elements in Medicine 1991, 8(1), 1-5.

21. Ducros, F.; Favier, A. J. Chromat. 1992, 583, 35-44. 
22. Handelman, G.J.; Kosted, P.; Shot, S.; Dratz, E.A. Anal. Chem. 1989, 61, 2244-2249.

23. Morisi, G.; Patriarca, Mk.; Menotti A., Clin. Chem. 1988, 34, 127-130.

24. Moynier I., Bourret E., Fussellier M., et Bardet L., Analusis 1989, 17, (7), 369-375.

26. Gille Revel, Les Techniques de l'ingénieur: traité, analyse et caractérisation, P2, art. 565, 1999, 1-21.

27. Rich C., Heimburger R., Maier-Sargentini L., Maier E., Rastegar F., Leroy M.J.F. Analusis 1987, 15, 159-167.
28. Simonoff M., Hamon C., Moretto P., Llabrador Y., and Simonoff G., Nuclear Instruments and Methods 1988, B31, $442-448$

29. Chapuis, P. (coordinator), (SFERETE) Techniques d'analyse des Oligo éléments; Paris: Lavoisier Tec \& doc. 1995, pp 149158.

30. Sommer F., Chevallier P., Tapiero H., Massiot P., Galle P., Silvestro L., Ariziti P., Picot D., Vacuum 1991, 42, 801.

31. Oster, O.; Schmiedel, G. and Prellwitz,W., Biological Trace element Research 1988, 15, 23-45. 